\title{
The Role of the Home-Based Provider in Disaster Preparedness of a Vulnerable Population
}

\author{
Tamar Wyte-Lake Maria Claver Anne Griffin Aram Dobalian \\ Veterans Emergency Management Evaluation Center (VEMEC), Sepulveda, Calif., USA
}

\section{Key Words}

Disaster $\cdot$ Home-based primary care $\cdot$ Strategies

\begin{abstract}
Background: Veterans receiving home-based primary care (HBPC) are an especially vulnerable population served by the Veterans Health Administration (VHA) due to high rates of physical, functional, and psychological limitations. These vulnerabilities may prevent these persons from being adequately prepared for disasters. HBPC providers connect the community-dwelling population with their regional health care system and thus are appropriate partners for assessing preparedness. The limited literature on this topic suggests that there are issues with the development and implementation of emergency management plans, dissemination to staff, and inconsistencies with preparedness strategies across agencies. Objective: To further explore identified issues regarding emergency management planning for pa-
\end{abstract}

tients receiving medical care in their home, including ways in which policy and procedures support the routine assessment of disaster preparedness for patients. Methods: This exploratory pilot project, carried out in a single VHA HBPC program located in an urban area, involved seven 15- to 25min semistructured interviews with practitioners and leadership. Transcripts of the interviews were analyzed using content analysis techniques to develop themes to describe information obtained through the interviews. Results: Six themes emerged from the data: (1) a national policy regarding the inclusion of disaster preparedness assessment in routine HBPC assessment exists in only a skeletal manner and individual HBPC programs are tasked with developing their own policies; (2) the tools used at the initial assessment were rudimentary and, in some cases, individually developed by providers; (3) the comprehension of criteria for assigning risk categories (i.e. acuity levels) varied among providers; (4) the primary challenges identified by respondents to patient engagement in emergency preparedness activities included

\section{KARGER}

E-Mail karger@karger.com

www.karger.com/ger
(C) 2014 S. Karger AG, Basel

0304-324X/14/0604-0336\$39.50/0
Dr. Tamar Wyte-Lake

Veterans Emergency Management Evaluation Center

16111 Plummer St. MS-152

Sepulveda, CA 91343 (USA)

E-Mail tamar.wyte@va.gov 
cognitive impairments, patients' willingness to invest in preparedness activities, and limited resources; (5) providers received limited formal training on how to prepare their patients for a disaster, and (6) provider recommendations included training to focus on better strategies to get patients to participate, more consistent time spent on patient education, formalization of the initial assessment, and having emergency preparedness be formally addressed on a more consistent basis. Conclusion: Formal standardized strategies regarding disaster preparedness assessment for HBPC patients, which leave room for flexibility in consideration of local factors, could assist in creating more comprehensive emergency management planning agendas and community collaboration.

c 2014 S. Karger AG, Basel

\section{Introduction}

Approximately 7.6 million individuals receive medical care in their homes because of acute illness, long-term care conditions, permanent disability, or terminal illness [1]. Chronic conditions, combined with normal physical, sensory, and cognitive changes that accompany aging, put homebound individuals at a heightened risk of harm during a disaster and they may need special support in the case of an emergency or disaster. In fact, 13 million persons aged 50 years or older in the USA say they would need help to evacuate, and about half of these individuals will require help from someone outside of their household [2].

\section{Caring for Homebound Veterans}

The Veterans Health Administration (VHA) HomeBased Primary Care (HBPC) program was created by the VHA with the express focus of delivering comprehensive primary care in the home, where HBPC becomes the primary care provider for its veteran constituents. It utilizes a highly interdisciplinary approach and the core team is generally composed of a physician, nurses (RNs), a social worker, rehabilitation therapists, a pharmacist, a dietitian, and psychologists. The HBPC program selectively targets individuals with complex chronic diseases and provides comprehensive primary care for months or years [3].

The proportion of male veterans aged 85 years and over increased from 33\% in 2000 to $68 \%$ in 2010 . The elder American veteran population has a higher percentage of functional limitations in activities of daily living or instrumental activities of daily living, a greater likelihood of

The Role of the Home-Based Provider in Disaster Preparedness having any disability, and a lesser likelihood of rating their general health status as 'good or better' than older adults in the general population [4]. Thus, the increase in this oldest segment of the veteran population will continue to have significant ramifications for the demand for health care services, particularly in the area of long-term care [5]. The HBPC population has a mean age of 76.5 years, its patient population has on average 8 or more chronic conditions, and $47 \%$ are dependent on two or more activities of daily living [3]. Although there may be a wide range of functional abilities and needs in this population, veterans receiving HBPC are an especially vulnerable population served by the VHA due to high rates of physical, functional, and psychological limitations. These vulnerabilities may prevent VHA HBPC patients from being adequately prepared for disasters.

\section{Home Health Care Providers and Disaster \\ Preparedness}

There is an absence of published literature on disaster preparedness activities benefiting the HBPC patient. However, there is literature addressing the next best alternative population, i.e. homebound patients receiving medical care from sources other than the US Department of Veterans Affairs (VA). These patients receive care from a home health agency (HHA), generally defined as a home care provider that is Medicare certified and provides skilled services in the home [6]. In contrast to the type of patient the HBPC serves, HHAs provide focused skilled care to patients with short-term conditions following acute care or a health care episode necessitating care [3]. Patients eligible for Medicare qualify for home care if it is established by a physician that they are confined to their home and need skilled nursing care and/or therapy (physical, occupational, or speech) on an intermittent basis. Their eligibility for home care is then reviewed every 60 days and a patient may have an unlimited number of episodes [7]. Although the length of time spent caring for patients may be shorter, HHA providers connect the community-dwelling population with the regional health care system and thus are appropriate partners for assessing preparedness and a reliable source for further information about this topic.

Several agencies have dedicated their efforts to developing emergency preparedness guidelines for HHAs. Two notable examples include the 2008 Emergency Preparedness Packet for Home Health Agencies of the National Association for Home Care and Hospices [6] and the 2011 Home Health Patient Assessment Tools: Preparing for Emergency Triage of the Agency for Healthcare 
Research and Quality (AHRQ) [1]. It is unclear how widely these guidelines have been disseminated. The limited research in this area has demonstrated that, although the majority of HHAs have documentation of minimum disaster preparedness plans required for certification, awareness of these plans by practitioners in these programs is low, and plans do not appear to be exercised, drilled, or used in practice [8,9]. Additionally, little consistency exists between the disaster plans of HHAs, even regionally [10], which impedes communication between them and local government agencies because of a lack of standard terminology [1]. Finally, most of the existing literature concentrates on the disaster preparedness plans of the agency but does not indicate how the providers assess or prepare their own homebound patients.

The literature reviewed for this study concurred with Laditka et al. [9] in that the majority of the existing literature about HHAs and disaster preparedness focuses on case studies that feature postdisaster experiences of HHA programs and providers. One such study describes the experiences of a single HHA in the aftermath of a local hurricane. Patient preparedness ranged from appropriate, early evacuation, to those patients who were sheltering themselves safely in place, to those whose electricitydependent equipment was not functioning and so they had to be evacuated to the most immediate postdisaster hospital. It was noted that it was fortunate that providers were able to get out to patients immediately after the event, as this is not always the case [11]. Of the 5 empirical studies identified by the literature review for this study, all focused on the perspective of leadership rather than the inclusion of HHA practitioners [1, 8-12]. Only 1 of the 5 identified studies evaluated the usefulness or accuracy of patient assessment tools for emergency planning, and it was focused on patient risk classification systems only rather than general patient disaster preparedness assessment [1].

Despite the dearth of published literature on disaster preparedness activities benefiting the HBPC patient, our review of the literature addressing nonveteran homebound patients receiving medical care has highlighted issues regarding emergency management plans and their dissemination to staff, practicality, consistency across agencies and uneven focus on the agency versus the patient's unique vulnerabilities. Therefore, this pilot aims to contribute to a better understanding of these issues by including providers, which allows us to examine the extent to which the perspectives of leadership and providers about policy and practice regarding patient disaster assessment are in agreement. Moreover, it focuses on un- derstanding disaster preparedness assessment among a vulnerable population, i.e. veterans who receive VA care, which has not yet been studied. In this paper, we aim to identify ways in which HBPC policy and procedures support routine assessment of disaster preparedness for its patients.

\section{Methods}

\section{Study Design}

HBPC providers from a single VHA medical center located in an urban area serving a diverse veteran population participated in this pilot, which involved a 15- to 25-min telephone interview. The semistructured interviews were directed by an interview guide (see online supplementary material, www.karger.com/ doi/10.1159/000355660) asking respondents to discuss disaster preparedness assessment procedures at an HBPC patient's initial evaluation (e.g. if existing forms are consistently completed), the frequency of reevaluation, whether disaster preparedness is included in the reevaluation, and what actions follow to improve disaster preparedness in response to the initial assessment (e.g. the development of an action plan). In addition, we requested the HBPC emergency management and disaster guide and assessment tools from the leadership described above.

One member of the research team conducted the interview and at least one member of the research team took notes during the interview. The interviews were audio recorded with the permission of the study participants. The audio recordings of interviews were transcribed and the transcripts were analyzed using qualitative content analysis. Once the data was collected, project members jointly developed the list of codes using both an inductive 'grounded theory' development of codes and a deductive organizational framework (i.e. an initial list) based on the major domains of the interview guide $[13,14]$. Two members of the team independently coded the data, with team members coming together to discuss discrepancies and resolving those by consensus.

\section{Results}

The 7 study participants included individuals in leadership positions (e.g. associated chief of staff and program manager), as well as HBPC practitioners in disciplines such as nursing, occupational therapy, social work, and psychology. Six themes emerged from the data: (1) policy regarding assessment of disaster preparedness, (2) disaster preparedness as part of initial assessments, (3) emergency risk categorization, (4) provider perception of the level of patient preparedness, (5) practitioner training about patient disaster preparedness assessment, and (6) provider recommendations for improvement of the program. Table 1 includes select quotations highlighting qualitative findings. 
Table 1. Leadership and provider perceptions of disaster preparedness activities

\begin{tabular}{ll}
\hline Theme & Illustrative quotes \\
\hline $\begin{array}{l}\text { Policy regarding } \\
\text { assessment of } \\
\text { disaster preparedness }\end{array}$ & $\begin{array}{l}\text { [When I got hired], I realized that whatever policies and procedures we did have needed [to be] } \\
\text { revised. And Joint Commission would be coming within as early as four months after I started, and } \\
\text { so I went to XX VHA HBPC and I looked at their policy and procedure manual. And many of our } \\
\text { policies I adapted from XX VHA HBPC, the VHA handbook and then also Joint Commission's. } \\
\text { (program manager) }\end{array}$ \\
\hline $\begin{array}{l}\text { Disaster preparedness } \\
\text { as part of initial } \\
\text { assessments }\end{array}$ & $\begin{array}{l}\text { The big emphasis I've been placing is telling people if they have an opportunity to grab their } \\
\text { medications. Keep a Vons bag close by and throw the bottles in the bag, in case the VA is not able to } \\
\text { fill a medication or if they're out, that they may be able to go to a local pharmacy and purchase a few } \\
\text { pills, if they're open. That's the biggest thing that I've done. I've started emphasizing that more. } \\
(O T)\end{array}$
\end{tabular}

Emergency risk

categorization

Q: Are the people on oxygen automatically considered a high risk, or does it depend on the disaster?

A: I would say no, it depends on that number that they're provided ... you know, that the provider gives them when they're initially admitted.

Q: Just personally, when you're thinking about your 1,2 and 3, are you taking into account if a caregiver is present on a regular basis?

A: Absolutely.

Q: Do you have a list that you determine or is it a subjective scoring? Like are there criteria that makes someone a 1, 2 or 3 or is it a subjective judgment?

A: No, there are criteria. So, for instance, I have my severity list. So a 1 ... so if you live in a facility where there's staff there around the clock, I know that you always have help, so that's a 1. So, there are actually criteria that ... and I'm not sure how. I guess it's over time the criteria got established by different managers, different staff or what have you, but that's just for an example. So if you have one bedroom that's in a locked facility, he has pretty severe dementia, so there's staff there $24 \times 7$ to take care of him. He would be a 1 .

Q: What if he was on a ventilator and he had $24 \mathrm{~h}$ staff. Would he be a 1 ?

A: I would probably say, if he was at home ...?

Q: Yeah, with 24 h staff.

A: With just a family or with a licensed person?

Q: Say a licensed person.

A: Okay, I would probably identify it as a 1 . Now, if it was a family member I might identify it as a 2. $(N P)$

Q: If you had a patient who maybe had a high acuity on, oxygen and everything but they had full-time caregivers - professional caregivers - how would they be rated in the risk category?

A: They'll probably be in a high risk because we would go with the highest that they were categorized in, I guess you could say. So a high risk category would be a patient who requires oxygen at all times. Q: If you receive oxygen you're an automatic 3 ?

A: Yes. Or a patient ... let's see here. The patient needs essential equipment that is dependent on electricity or will need to be hospitalized in the event of an emergency that interrupts utilities. So they would be an automatic 3 .

(RN; clinical assistant manager)

Provider perception

of the level of patient preparedness
And then [during the mock phone tree cascade] we ask them [the patients] questions and they give us feedback. The RNs went out and did further education to the patients and documented that. I mean, one person said to us, well - you know, I said: 'What would you do if the lights went out and you couldn't see?' And he said: 'Well, I'd light my lighter.' That's very concerning. In [certain disaster situations] you have gas leaks. So if you light your lighter, your whole house is going to burn down. (program manager)

So, I think we make the effort to make it safe. So I would say I think pretty well prepared, but again, like I said, there's always going to be the outliers who are just going to be praying, unfortunately, and that's always in health care. But I think where we see the opportunity, we definitely take it. $(N P)$
The Role of the Home-Based Provider in Disaster Preparedness 
Table 1. (continued)

\begin{tabular}{ll}
\hline Theme & Illustrative quotes \\
\hline $\begin{array}{l}\text { Practitioner disaster } \\
\text { preparedness training }\end{array}$ & $\begin{array}{l}\text { That's a good question. Well, we think what we have in our brain would be okay, but generally no, we } \\
\text { don't have like a detailed plan if they say they're not okay. For our patients who are on oxygen we } \\
\text { have discussed with our oxygen company that we have a contract with as to what to do, and they said } \\
\text { that we can notify them. And then, of course, if there's roads down and they can't get to them, of } \\
\text { course, the patient will have to call 9-1-1, but other than that we'd pretty much do what we can based } \\
\text { on what type of disaster and what we're dealing with. } \\
(R N)\end{array}$ \\
\hline $\begin{array}{l}\text { Provider } \\
\text { recommendations for } \\
\text { improvement of the } \\
\text { program }\end{array}$ & $\begin{array}{l}\text { I think we addressed it as a team. We talk about it, but I think it has to be more - when I say } \\
\text { formalized, it has to be part of the treatment plan and that has to be constantly be reviewed and as } \\
\text { things change, obviously. So, you know, I think we do it - it's a matter of what we do in terms of all } \\
\text { our disciplines, but we just need to formalize it. } \\
\text { (social worker) }\end{array}$ \\
\hline
\end{tabular}

Policy Regarding Assessment of Disaster Preparedness

According to this study's respondents, national policy regarding the inclusion of disaster preparedness assessment in routine HBPC assessment exists in only a skeletal manner, citing as an example the guidelines of the Joint Commission. Rather, individual VHA medical center HBPC programs are tasked with developing their own policies. In this study, the HBPC program director developed a disaster preparedness assessment policy based on the policy of another VA medical center HBPC program that seemed appropriate and well organized. The director had to adjust the policy to meet the needs of this particular VA medical center to reflect the need to assess preparedness for unique local parameters such as extreme weather emergencies.

At this study site, in general, when a patient is first admitted to the HBPC program an initial intake patient assessment is completed by the lead practitioner, usually a nurse practitioner (NP) and sometimes an RN. Within 30 days of this intake, all team members need to have met with the veteran to assess detailed needs according to the provider's discipline, after which the interdisciplinary team meets to discuss the patient care plan. The formal interdisciplinary team meeting occurs at the 90-day mark after patient admission. Initial assessments by all practitioners are discussed at the 30-day interdisciplinary team meeting, and all issues are expected to have been addressed by the 90-day review. The patient's case is then reviewed every 90 days, also at the formal interdisciplinary meeting. The frequency of reassessment varies depending on the discipline, although respondents from all of the represented disciplines mentioned that reassessment may occur more frequently than the guidelines suggest if there has been a change in the patient's condition or situation. According to study respondents, an initial, cursory emergency risk assessment is completed by the lead practitioner at the time of the initial assessment for entry into the program. A more intensive emergency risk assessment is then conducted within 30 days by the occupational therapist (OT) assigned to the patient.

\section{Disaster Preparedness as Part of the Initial \\ Assessment}

At the initial evaluation, the patient is provided with an information handbook which is reviewed with the patient by the provider opening the case. Leadership indicated that the section of the handbook on disaster preparedness is reviewed with the patient (and a caregiver, if present) by the lead practitioner upon admission, and that this review includes information related to keeping medication and what to do for geriatric patients when there is an emergency, and things like that'.

As mentioned earlier, at this facility, the NP is generally considered the primary care provider for the HBPC patient, and either the NP or an RN opens the case. Regarding the actual practice of including disaster preparedness assessment upon admission, the NP commented: 'We do touch on some issues with regards to disaster planning and emergency planning.' This initial assessment includes basic disaster preparedness information such as asking the patient how he would evacuate his home in the case of an emergency, the presence of smoke detectors, running water, and adequate heat- 
Table 2. Items included in the risk classification system

\begin{tabular}{ll}
\hline Risk classification & $1=$ minimal risk \\
& $2=$ moderate risk \\
& $3=$ high risk \\
\hline Is the patient on oxygen? & Yes \\
& No \\
\hline Is the patient prepared for extreme weather & Yes \\
conditions? & No \\
\hline
\end{tabular}

Caregiver contact information

ing and air conditioning. She/he also assesses the availability of a caregiver in emergency situations. It was noted in the provider interviews that although there was awareness on the part of providers of the disaster preparedness section of the handbook, it was not often reviewed with the patients, nor was the content very familiar to the providers.

All respondents noted that although a preliminary disaster preparedness assessment is conducted at the initial assessment for inclusion into the HBPC program, and each provider may contribute to the disaster preparedness of the patient, the providers most responsible for the disaster preparedness assessment, and any follow-up activities, were the OTs on the team. When asked what type of assessment form or instruments are used to guide and document the initial assessment, an OT responded: 'We have a template that we use. That's something I made up a long time ago ... the [other] OT uses one and I think hers is a little different ...' Q: 'So it is not a formal form used by all practitioners?' A: 'No, no, we just developed it.' When the template itself was reviewed by the study team, there was a single area for a check mark under patient/family education making sure that the 'emergency plan [had been] discussed'. The OT explained '... if there's something specific that I discussed with them, like making sure they have extra water, that we talked about grabbing their medications, that we talked about an escape route ... then I will document that additionally'. Practitioner responders commented that they thought the OT might provide additional information, but the OT mentioned very little additional information about disaster preparedness provided to the patient and his family. One of the respondents admitted: 'Maybe I should be kind of doing some more reminders about things, but I do feel like our team works pretty well and so I kind of have just trusted that it's being taken care of by other people.'

The Role of the Home-Based Provider in Disaster Preparedness

\section{Emergency Risk Categorization}

When a patient is first admitted into the HBPC program, the NP is tasked with assigning an acuity level, that is, the level of risk for additional assistance in the case of a disaster (table 2). At this site, the acuity level ranged from 1 (minimal risk) to 3 (high risk) and was based on the findings of the initial assessment. A roster of patients with their assigned acuity levels is distributed to all team members. In addition to the risk category, a note is made in the patient's medical record as to whether the patient is on oxygen and if they are prepared for extreme heat (with air conditioning or access to a cooling center) or extreme cold (with heating). Notes about the assessment are recorded as an initial note in the Computerized $\mathrm{Pa}$ tient Record System (CPRS), the computerized medical record system of the VA. The note has to be electronically 'signed' by all of the team members to document acknowledgement that they have read the assessment results.

There was some variation in information given about how a patient is assigned to a particular risk category (i.e. acuity level) depending on the practitioner interviewed. When queried to describe the breakdown of the risk categories, two respondents specifically read to the interviewers the acuity guidelines specified in the local HBPC handbook, but neither was actively involved in assessing patient acuity levels. The NP, who seemed to be one of the primary persons assigning the acuity rating according to several of the respondents, shared that: 'There's a guide, but I think really, it's operator dependent.' She continued to comment that: 'Even though there's a guide, I mean, we don't ever discuss what rating, if you will, for an acuity rating we have assigned the patient. It's never discussed in our team meetings. We don't talk about that and we don't ever get questions about it.' This input was contrary to information received by the administration, which indicated that the risk acuity rating was determined by the entire team at the initial interdisciplinary team meeting.

Two respondents, although neither was tasked with determining the risk categorization for patients, contributed information that further explained the determination of a risk category regarding disaster preparedness. They explained that a patient's risk acuity rating may differ according to the type of disaster in question. One may be a rating of 1 for a general disaster, but a 3 for an extreme heat wave. When the research team presented practitioner respondents with the same scenario about a patient on a ventilator with around-the-clock caregiver support, different practitioners gave different disaster risk category ratings. 
All of the respondents, regardless of the discipline, reported feeling comfortable with providing input about a patient's risk categorization level although, admittedly, according to the NP: 'There's never been an opportunity for me to see, like, okay, my colleague would have assigned them a different number.'

\section{Provider Perception of the Level of Patient \\ Preparedness}

When queried about providers' perceptions of patient preparedness, many providers spoke of the challenges of working with the HBPC population on disaster preparedness activities. The three primary challenges included cognitive impairments, difficulty with a patient's willingness to 'buy in' or cooperate with preparedness activities, and limited resources. Cognitive impairments affected the ability of a patient to implement recommendations. As one respondent noted: 'The other thing you always have to factor in is so many of these people have cognitive problems. I mean, they lose their handbook every time you see them. So what they tell you they've been told and what they've been told can be very different.' Difficulty with buying in and resources were interrelated, as providers reported that oftentimes since patients did not really feel a need to put a disaster kit together, and if they had limited financial resources (to purchase) and transportation resources (to get to the store) to begin with, the preparedness kit never rose to a high enough priority level to be actualized.

Providers were split in their sense of patients' actual preparedness levels, although those providers who spent more time on this aspect of patient care were less confident of the patients' levels of preparedness. One provider reported that during a power outage, a patient on a ventilator had a backup generator, but it did not work. Up until that point, there had been no standard practice of routinely checking backup generators. Although the providers now seemed more aware of the issue, there was no mention of a standard protocol to address it. Another provider felt that the patients were as prepared as possible when they put into effect standard safety measures such as medical alert systems, caregiver education, and medical alert bracelets as well as home modifications to make exits out of the home as easy and safe as possible.

\section{Practitioner Training about Patient Disaster \\ Preparedness}

None of the providers reported having been provided with any specific training on how to prepare their HBPC patients for a disaster. Leadership did mention trying to include mini in-services throughout the year, but none of the providers mentioned those when probed. When asked if they had been given instructions on what to do if they called a patient and found that they were not okay, respondents mentioned that they rely on their personal knowledge.

Four of the 7 respondents described practicing a phone tree cascade when asked about activities undertaken to prepare the staff for how to respond in a disaster. The reported frequency of this activity ranged from once a year to about 6 times over the last 3 years. Generally, the phone tree cascade was limited to a practice run calling all providers to ensure that all were 'okay' after a mock disaster. One respondent mentioned that the providers have a script detailing what should be discussed with a patient in an emergency, in the case that the phone tree cascade is initiated. The NP and leadership also described one experience where they included patient calls in the mock phone tree cascade as well (table 1). As respondents were not explicitly asked about what was done with the results of the mock disaster exercises, it is unclear if any of this information was then used to strengthen the disaster preparedness activities of the team, as no follow-up activities were mentioned and respondents were not specifically asked about this issue.

Experience with previous disasters seems to have informed the majority of preparedness among the leadership and providers. Three of the respondents mentioned having experienced a major regional disaster more than 10 years ago as practitioners, with two having been providers with the same HBPC program. All three of these respondents alluded to the fact that they, as well as the general world of health care for emergency management, had learned from mistakes made in previous disaster experiences.

\section{Provider Recommendations for Improvement of the Program}

Numerous suggestions were made for recommendations for the disaster preparedness component of the HBPC program. Formalization of the training and program came up in 4 of the 7 interviews. Providers recommended: (1) training to focus on better strategies to get patients to participate, (2) more consistent time spent on patient education, (3) formalizing the initial assessment to actually evaluate how prepared patients are, and (4) having emergency preparedness be formally addressed on a more consistent basis, possibly in the annual interdisciplinary review of each patient.

Issues regarding the phone tree were also raised. One provider was not aware of who was assigned to make patient calls in preparation for severe weather conditions. 
Two providers mentioned that there could be more people involved in calling patients after a disaster. For example, although RNs and NPs were generally assigned the highest-risk patients because of medical acuity, social workers and OTs could be engaged in calling the lowest-risk patients because often they just need assurance that all is okay.

\section{Discussion}

In general, there appears to be room for improvement when it comes to disaster preparedness assessment among HBPC patients. Individual HBPC programs seem to be on their own regarding the creation of policy about assessment for patient disaster preparedness as no national VHA HBPC policy about it exists to the knowledge of this study's respondents. Although well-recognized associations such as the National Association for Home Care and Hospice [6] and the AHRQ [1] have released guidelines with regard to disaster preparedness, none of the respondents were aware of these national guidelines.

As noted in earlier, the limited existing literature on the topic of disaster preparedness among home care providers focused on speaking with the leadership $[1,8-12]$. Within this particular HBPC program, there were significant discrepancies between what the leadership reported regarding policy and what providers reported doing in practice. Although all respondents interviewed for this study seemed eager to comply with the disaster preparedness regulations and gain training to be even better prepared, a significant policy-practice gap exists. As the success of the preparedness plan depends on consistency throughout the team, the gap is of particular concern when it comes to assessing patients appropriately. This topic deserves further exploration in the future.

The assessment tools used by providers for disaster preparedness have not been standardized at this HBPC program, in that each of the two OTs primarily responsible for disaster preparedness assessment have created their own assessment tools. Furthermore, the assessments have been revised to reflect the individual perceptions of what is important based on experiences with patients. One example is the inclusion of testing generators because of several patients' experiences with dealing with a nonfunctioning generator. It was unclear whether the result was a change in the formal policy to include regular testing of generators or if the OT performs the activity ad hoc. Additionally, it is unclear how much consultation occurs between the two OTs that use and revise the as- sessment tool. While revision of the tool based on observations in the field may be an effective approach to keeping the tool relevant, it seems that a formal review of the tool by all members of the team and the creation of a standard tool for disaster preparedness assessment may ensure that the assessment and subsequent recommendations for improvement of disaster preparedness would be useful.

A factor that may contribute to some of the issues targeted for improvement as a result of this study may be that those that are not directly involved with disaster preparedness assessment seem to be uninvolved in this aspect of care, other than in receiving an acuity list. The social worker would like to be more involved, while the psychologist seems to be comfortable leaving it to others, even though for some veterans with mental health issues the psychologist seems to be the team member that sees the patients most frequently. Having every team member involved to a large extent is likely unworkable, as one person needs to be primarily responsible to prevent issues from falling through the cracks. Nonetheless, there is likely room for more input from those providers who see the patients on a more regular basis. Additionally, all providers should receive training, as there are often natural opportunities that arise during a care session to incorporate disaster preparedness activities or trainings with the patient.

Although the responsibility for the more intensive evaluation falls to the OTs at this program, it is not expected that this is the case at all VHA HBPC programs. We suspect that OTs, being responsible for functional rehabilitation and focused on activities of daily living, were the most natural service group to take responsibility for this activity. Future studies should also explore to what extent the responsibility to do the intensive disaster preparedness assessment consistently falls to particular service groups.

Additional uncertainty arose regarding the primary responsibility of assigning a risk category to each patient. First, the NP has the responsibility to assign a risk category to the patient. One of the administrative participants reported that the entire interdisciplinary team plays a more significant role in determining a risk category for each patient than was mentioned by any of the other study participants. Second, although there is agreement that a risk category of 1 indicates the lowest risk, a 2 indicates moderate risk, and a 3 indicates the highest risk, there was some discrepancy as to how the availability of a caregiver factors into the risk categorization. For example, one study participant explained that anyone with a 
caregiver, regardless of physical frailty, would be assigned to the lowest risk category because of the availability of the caregiver, while another study participant remarked that, regardless of the availability of a caregiver, a person with significant physical frailty would be placed in the highest risk category. When given a brief patient scenario, provider respondents assigned different risk categories. Home Health Patient Assessment Tools: Preparing for Emergency Triage [1] attempts to provide standardization to the field and discusses the need to move away from numbered risk categories (e.g. $1=$ high risk and $3=$ low risk), rather recommending the standardization of 'high', 'medium', and 'low' so that understanding of the category will be clear to persons both inside and outside of the agency. This program had not adopted those recommendations, nor did this program's providers indicate knowledge of them. Additionally, the only study that was found that evaluated the usefulness or accuracy of patient assessment tools for emergency planning was the AHRQ study [1], which looked solely at the patient classification system. A search of the current literature failed to identify a published evaluation of the guidelines of the AHRQ. Future research should examine risk categorization in terms of utility and interrater reliability. For example, a study could use scenarios that ask participants to assign risk categories to determine consistency across disciplines and between providers tasked with assessing risk.

The implementation of patient education about disaster preparedness, according to participants, could be more comprehensive. While several providers mentioned the inclusion of disaster preparedness in a patient handbook provided to all patients and their caregivers, none described reviewing the materials with the patient or supporting the patient in assembling an emergency kit.

Perhaps many of the challenges described by the study participants could be addressed with training about how to assess disaster preparedness and contribute to a plan of care based on the results. Overall, the participants felt there was a lack of training specific to the assessment and implementation of disaster preparedness for HBPC patients. This finding concurred with those of previous research $[8,9]$. The care providers in this study felt that, although they receive general disaster preparedness training as a VA employee, they have not received any or adequate training specific to the needs of patients in HBPC, including how to assess a patient for disaster preparedness. The leadership that participated in this study, however, commented on attempts to incorporate training about patient disaster preparedness into each meeting, rather than providing targeted training about this issue.
Finally, in addition to challenges at the program level that might be addressed to improve the assessment of disaster preparedness for HBPC patients, respondents identified patient characteristics that create challenges related to preparedness, such as cognitive impairment, a lack of resources to prepare an emergency kit, and low interest in completing preparedness activities. The patient characteristics mentioned by the respondents in this study echo the biological, psychological, and social needs of vulnerable populations in a disaster identified by others $[9,15-25]$.

While our study has provided insight into how an HBPC program prepares for disasters, several limitations should be recognized. One of the limitations is that this is a single-site study, with a sample size of 7 respondents, and thus might not be generalizable to all HBPC programs or all patients receiving care at home. The sample size for this study was limited, but previous studies about this topic have also had relatively small sample sizes. Moreover, as with our study, other studies have been restricted geographically to the south or west coast of the USA $[8,9,12]$, and only one has examined the issue nationally [1]. Thus, as both Daugherty et al. [8] and Ladit$\mathrm{ka}$ et al. [9] noted, the literature would benefit from a broader and more representative sample of states from across the nation. Another limitation of this study is that its limited scope focused primarily on policy, provider activities, training opportunities, and assessment tools. It did not allow for extensive exploration into what was done with the results of activities such as the disaster drills.

Although there is a great deal of variation between HHAs, and even between HHAs and the HBPC program, the use of a more general hazards vulnerability assessment should be considered. Although each program will have its own regional and institutional considerations for disaster preparedness, there are several factors that may be common to patients receiving care in the home regardless of geographic location or type of disaster, such as extreme heat, electricity outages, preparation for evacuation, and an understanding of how to shelter in place [1, 21-23]. Although the respondents seemed interested in optimizing their preparedness plans, the field seems not to have taken the initiative to inform itself of the numerous resources available. Additionally, although there are existing guidelines, they need to be evaluated for effectiveness. Finally, the ad hoc nature of the adoption of disaster preparedness plans and assessment strategies prevents them from sharing information with other community organizations that would need that information to 
assist in helping with evacuation or other types of support necessary during an emergency. More formal and standardized strategies, which still leave room for flexibility in consideration of local factors, could assist in creating more comprehensive planning agendas.

The views expressed in this article are those of the authors and do not necessarily reflect the position or policy of the VA or the US government.

\section{Acknowledgment}

This material is based upon work supported by the Department of Veterans Affairs, Veterans Health Administration, Office of Public Health, and the Office of Public Health Preparedness and Response. The findings and conclusions in this article are those of the authors and do not necessarily represent the views or policies of the Department of Veterans Affairs, or the U.S. government.

\section{References}

1 Zane R, Biddinger P: Home Health Patient Assessment Tools: Preparing for Emergency Triage. Agency for Healthcare Research and Quality publication 11-M020-EF. Rockville, AHRQ, 2011. http://archive.ahrq.gov/prep/ homehealth/homehealth.pdf.

2 Gibson MJ: We Can Do Better: Lessons Learned for Protecting Older Persons in Disasters. Washington, AARP, 2006.

$\checkmark 3$ Beales JL, Edes T: Veteran's Affairs Home Based Primary Care. Clin Geriatr Med 2009; 25:149-154.

-4 Selim AJ, Berlowitz DR, Fincke G, Cong Z, Rogers W, Haffer SC, Ren XS, Lee A, Qian SX, Miller DR, Spiro A 3rd, Selim BJ, Kazis LE: The health status of elderly veteran enrollees in the Veterans Health Administration. J Am Geriatr Soc 2004;52:1271-1276.

5 Federal Interagency Forum on Aging Related Statistics: Older Americans 2012: Key Indicators of Well-Being. Federal Interagency Forum on Aging-Related Statistics. Washington, US Government Printing Office, 2012. http://www.agingstats.gov/agingstatsdotnet/ Main_Site/Data/2012_Documents/Docs/ EntireChartbook.pdf.

6 National Association for Home Care and Hospice: Emergency Preparedness Packet for Home Health Agencies. Washington, National Association for Home Care and Hospice, 2008.

7 Binder C, Hahn J, Kirchhoff SM, Morgan PC, Tilson S: Medicare Primer (R40425). Washington, Congressional Research Service, 2013. www.crs.gov.

8 Daugherty JD, Eiring H, Blake S, Howard D: Disaster preparedness in home health and personal-care agencies: are they ready? Gerontology 2012;58:322-330.
-9 Laditka SB, Laditka JN, Cornman CB, Davis $\mathrm{CB}$, Chandlee MJ: Disaster preparedness for vulnerable persons receiving in-home, longterm care in South Carolina. Prehosp Disaster Med 2008;23:133-142.

10 Kirkpatrick DV, Bryan M: Hurricane emergency planning by home health providers serving the poor. J Health Care Poor Underserved 2007;18:299-314.

11 King R: The puzzle of Fran: Home healthcare in a hurricane. Home Healthcare Nurse 1998; 16:679-685.

12 Phreaner D, Jacoby I, Dreier S, McCoy N: Disaster preparedness of home health care agencies in San Diego County. J Emerg Med 1994; 12:811-818.

13 Glaser BG, Strauss AL: Status Passage. Hawthorne, Aldine De Gruyter, 2009.

14 Denzin NK, Lincoln YS: The discipline and practice of qualitative research; in Denkin NK, Lincoln YS (eds): Handbook of Qualitative Research, ed 2. Thousand Oaks, Sage, 2000.

15 Centers for Disease Control and Prevention: Public health workbook to define, locate, and reach special, vulnerable, and at-risk populations in an emergency (CS211575-A). 2010. http://www.bt.cdc.gov/workbook/pdf/ph workbookFINAL.pdf.

-16 Claver M, Dobalian A, Fickel JJ, Ricci KA, Mallers MH: Comprehensive care for vulnerable elderly veterans during disasters. Arch Gerontol Geriatr 2012;56:205-213.

17 Deal BJ, Fountain RA, Russell-Broaddus CA, Stanley-Hermanns M: Challenges and opportunities of nursing care in special-needs shelters. Disaster Manag Response 2006;4:100105.
18 Baylor College of Medicine, American Medical Association: Recommendations for best practices in the management of elderly disaster victims. 2006. http://www.bcm.edu/pdf/ bestpractices.pdf.

19 Banks L: Caring for elderly adults during disasters: improving health outcomes and recovery. South Med J 2013;106:94-98.

20 Johnson A, Howe JL, McBride MR, Palmisano BR, Perweiler EA, Roush RE, Sanders M, Sherman A, Tumosa N, Weiss J: Bioterrorism and Emergency Preparedness in Aging (BTEPA): HRSA-funded GEC collaboration for curricula and training. Gerontol Geriatr Educ 2006;26:63-86.

21 Bethel JW, Foreman AN, Burke SC: Disaster preparedness among medically vulnerable populations. Am J Prev Med 2011;40:139143.

22 Risoe P, Schlegelmilch J, Paturas J: Evacuation and sheltering of people with medical dependencies - knowledge gaps and barriers to national preparedness. Homeland Secur Aff 2013;9:article 2.

23 Rothman MB, Dunlop BD, Seff LR, Pekovic $\mathrm{V}$ : Disaster planning for older adults in Palm Beach County. North Miami, The Center on Aging, 2005.

24 Fernandez LS, Byard D, Lin CC, Benson S, Barbera JA: Frail elderly as disaster victims: emergency management strategies. Prehosp Disaster Med 2002;17:67-74.

25 Aldrich N, Benson WF: Disaster preparedness and the chronic disease needs of vulnerable older adults. Prev Chronic Dis 2008; 5:1-7. http://www.cdc.gov/pcd/issues/2008/ jan/07_0135.htm. 